represented nearly 70 per cent. The very low prices obtainable for the 1931 cereal crops influence these proportions, but even taking this into consideration, cereals can be described as an important cash product on the larger farms only. The success of the small farmer, and these form the majority, is more dependent on the price of livestock and feeding stuffs than on those of cereals. Interesting comparisons are made of the organisation of the agriculture of the principal farming localities of the province: for example, central Norfolk light loams, the Norfolk 'breck', central Suffolk heavy soils, south Essex London clays, south Cambridgeshire gravels, etc. The most depressed areas are the boulder clays of Essex and Suffolk, and the clays in west Cambridgeshire and Huntingdonshire. The report deals further with main factors influencing profits and with many other subjects of interest to administrators and to farmers.

\section{Electricity and the Farmer}

A PAPER read by F. E. Rowland at the Royal Agricultural Show, Southampton, on July 7 and printed by the B.E.D.A. (British Electrical Development Association, Inc.) of 15 Savoy Street, W.C.2, gives helpful hints to farmers as to the best way to apply electricity to their farms. The price of the unit is taken as $2 d$., and when it can be obtained at this price a good case is made out for using electric power. In many cases when space is limited, as in stackyards, electric drive has many advantages. 18 sheep can be sheared per unit expended, or 45 horses groomed, or 12 horses clipped. Motors can be rolled from one part of a farm to another inside wooden drums. Excellent and economical methods are given of lighting farm buildings and roads. Electrically driven pumps provide automatically a plentiful supply of water for all purposes. The use of electric milkers which require a $\frac{1}{2}-h . p$. motor is becoming widespread in England. In New Zealand 15,000 are in use. By the expenditure of one electric unit, 22 cows can be milked, $120 \mathrm{lb}$. of butter churned, or 1000 bottles washed. Accurate data are given as to the effect of poultry lighting in stimulating egg production.

\section{A New Journal of Animal Ecology}

$\mathrm{IT}_{\mathrm{T}}$ is gratifying to find that zoological analysis, having for long been largely confined to the laboratory, is being pushed with vigour into the open country, the obvious place for testing and resolving some of the big problems of animal life. So insistent has been the demand for space to publish the results of observations upon animal populations, their distribution, fluctuations in numbers, migrations and the like, and to concentrate observations of the kind for the convenience of field-workers and zoologists in general, that the British Ecological Society has decided to issue, twice a year, a Journal of Animal Ecology, under the editorship of Charles Elton, assisted by A. D. Middleton. The first number, which appeared in May from the Cambridge University Press, is an attractive volume, in appearance as well as in matter. It contains many-sided contributions, from studies of the fluctuations of insect populations in wheat and of bird numbers on an Oxfordshire farm, to a rookery census, an analysis of the ranging habits of wood-ants, and an account of the biology of the fruit-bats of Australia. There are many illustrations, and a useful reference list contains summaries of papers dealing with animal ecology. Members of the British Ecological Society (Secretary, Dr. H. Godwin, Botany School, Cambridge) obtain the Journal for their subscription of $25 s$., to non-members the price is $30 s$. The magazine promises to make a niche of its own in British zoological literature, and the interest of its outlook ought to draw many supporters. We understand that so far as suitable material is concerned its success is assured.

\section{Acta Phaenologica}

THE new bi-monthly international journal Acta Phaenologica aims at concentrating the hitherto scattered studies in phenology and offering an opportunity to "set forth various tendencies, stages of development, points of view of different centres of phenological experiment, and by giving a chance to consult on aims and methods, to achieve useful and active collaboration ". The journal is issued under the editorship of the board of the Phenological Association of the Netherlands, and in the first part (Sept. 1931: Publ. Martinus Nijhoff, The Hague) the Secretary, Dr. H. Bos, writes on the scope and prospects of phenology. In the same number there are articles by J. Edmund Clarke on "The Cold Spring of 1929 in the British Isles" and S. Illichevsky on "The Results of the Phenological Observations at Poltava (U.S.S.R.)". The second part includes contributions from Prof. Thne on "The Beginning of the Phenological Spring in Central Europe during the Ten Years' Period, 1921-1930", Prof. Poggenpohl on "Phenological Observations, 1886-1907", and Dr. H. Bos on "The Dropping of Small Fruits after Blooming ". Contributions are accepted in English, French, or German, and each is accompanied by a translation of its title and a short summary of the contents in the two other languages.

\section{Habits of the Woodpecker}

Although a tame woodpecker is mentioned by Aristotle, the birds of this family have never been favourites with aviarists, and even the London Zoological Society, after having exhibited at different times no less than seventeen species, had been without a specimen for years until a family of the British greater spotted species arrived recently, and were accommodated with a special cage in the Bird House. Here they attract attention by their extreme activity, which is very characteristic of woodpeckers ; they contrast in this respect with their nearest allies the barbets, of which several species are on view, much as tits do with finches. It is of interest to note, however, that the pair-toed feet, often supposed to be an adaptation for climbing, are to be found in the more primitive group of barbets, which do not climb, and that these peck wood when excavating a nesthole, although their beaks are not specialised into the chisel-type of the woodpeckers' bills, and they do not

$$
\text { No. 3283, Vor. 130] }
$$

